\title{
A MINIMUM COMPONENT GROUNDED-CAPACITOR CFOA-BASED RC OSCILLATOR
}

\author{
MUHAMMAD TAHER ABUELMA'ATTI* AND SA'AD \\ MUHAMMAD AL-SHAHRANI
}

King Fahd University of Petroleum and Minerals, Box 203 Dhahran 31261 Saudi Arabia

(Received January 30, 1996; In final form March 29, 1996)

A minimum-component grounded-capacitor single-frequency RC-sinusoidal oscillator circuit using the current feedback operational amplifier (CFOA) is presented. The circuit uses a single CFOA, two resistors, and two grounded capacitors. The circuit enjoys low active and passive sensitivity characteristics.

\section{INTRODUCTION}

Recently a number of single CFOA-based RC sinusoidal oscillators have been proposed [1-3]. Assuming ideal CFOA characteristics, the minimum number of passive components used, so far, is five. However, by exploiting the CFOA-pole it is possible to obtain a sinusoidal oscillator using only four externally-connected passive components [4]. In this paper, we explore the possibility of synthesizing an $\mathrm{RC}$ oscillator using an ideal CFOA and four externally connected passive components.

\section{CIRCUIT CONFIGURATION}

Consider the oscillator structure shown in Fig. 1. Assuming that the CFOA is ideal with $v_{x}=v_{y}, i_{z}=i_{x}, i_{y}=0$ and $v_{0}=v_{z}$, routine analysis yields the characteristic equation of this circuit configuration given by

$s^{2} C_{1} C_{2}+S\left(G_{1} C_{2}+G_{2} C_{1}-G_{1} C_{1}\right)+G_{1} G_{2}=0$

Using the Barkhausen principle, by equating the real and inmaginary parts of (1) to zero, the frequency and the condition of oscillation of the circuit of Fig. 1 can be expressed as

$\omega_{0}^{2}=\frac{G_{1} G_{2}}{C_{1} C_{2}}$

and

*Corresponding author. 


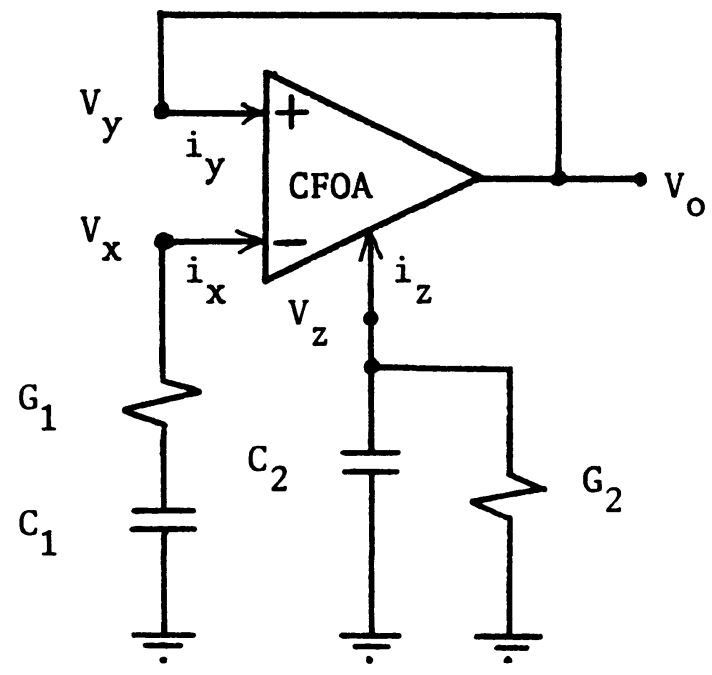

FIGURE 1 Proposed Oscillator Circuit.

$G_{1} C_{1}=G_{1} C_{2}+G_{2} C_{1}$

From (2) and (3) one can see that the frequency and the condition of oscillation are fully coupled. Thus, the proposed circuit of Fig. 1 is useful for realizing single frequency oscillators.

\section{EFFECT OF CURRENT- AND VOLTAGE-TRACKING ERRORS}

Taking into account the current- and voltage-tracking errors of the CFOA, namely $i_{z}=\alpha i_{x}, v_{x}=\beta v_{y}$ and $v_{o}=\gamma v_{z}$, where $\alpha=1-\psi_{1},\left|\psi_{1}\right|<<1$ represents the current tracking error of the CFOA, $\beta=1-\psi_{2},\left|\psi_{2}\right|<<1$ represents the input voltage tracking error of the CFOA and $\gamma=1-\psi_{3},\left|\psi_{3}\right|<<1$ represents the output voltage tracking error of the CFOA, the characteristic equation of (1) becomes

$s^{2} C_{1} C_{2}+s\left(G_{1} C_{2}+G_{2} C_{1}-\alpha \beta \gamma G_{1} C_{1}\right)+G_{1} G_{2}=0$

Using (4), it is easy to show that, while the frequency of oscillation of the circuit of Fig. 1 will not be affected by the CFOA nonidealities, the condition of oscillation will be

$\alpha \beta \gamma G_{1} C_{1}=G_{1} C_{2}+G_{2} C_{1}$

Thus, the condition of oscillation will be slightly affected by the CFOA current and voltage tracking errors. 


\section{EFFECT OF CFOA PARASITICS}

Taking into account the CFOA-parasitics, the CFOA can be modelled using the equivalent circuit shown in Fig. 2 . This model is obtained by adding a voltagecontrolled voltage-source to the plus-type second-generation current-conveyor $(\mathrm{CCII}+)$ model used by Svoboda [5]. Reanalysis of the structure of Fig. 1, using the CFOA model of Fig. 2, yields the characteristic equation that can be expressed as

$s^{2} C_{1} C_{2}+s\left(G_{1} C_{2}+G_{2} C_{1}-G_{1} C_{1}\right)+G_{1} G_{2}=\left(G_{z}+s C_{z}\right)\left(1+R_{x} Y_{1}\right)+R_{x} Y_{1} Y_{2}$

Using (6), the effect of the CFOA-parasitics on the frequency and condition of oscillations of the circuit of Fig. 1 can be calculated. With $C_{1} \gg C_{z}, C_{2} \gg C_{z}, G_{1}$ $.>G_{z}, R_{x} G_{1}<<1, G_{2} \gg G_{z}$, the frequency and the condition of oscillation can be approximated by

$\omega_{0}^{2} \cong \frac{G_{1} G_{2}}{C_{1} C_{2}\left(1-R_{x} G_{z}\right)}$

and

$G_{2} C_{2} \cong G_{1} C_{2}+G_{2} C_{1}$
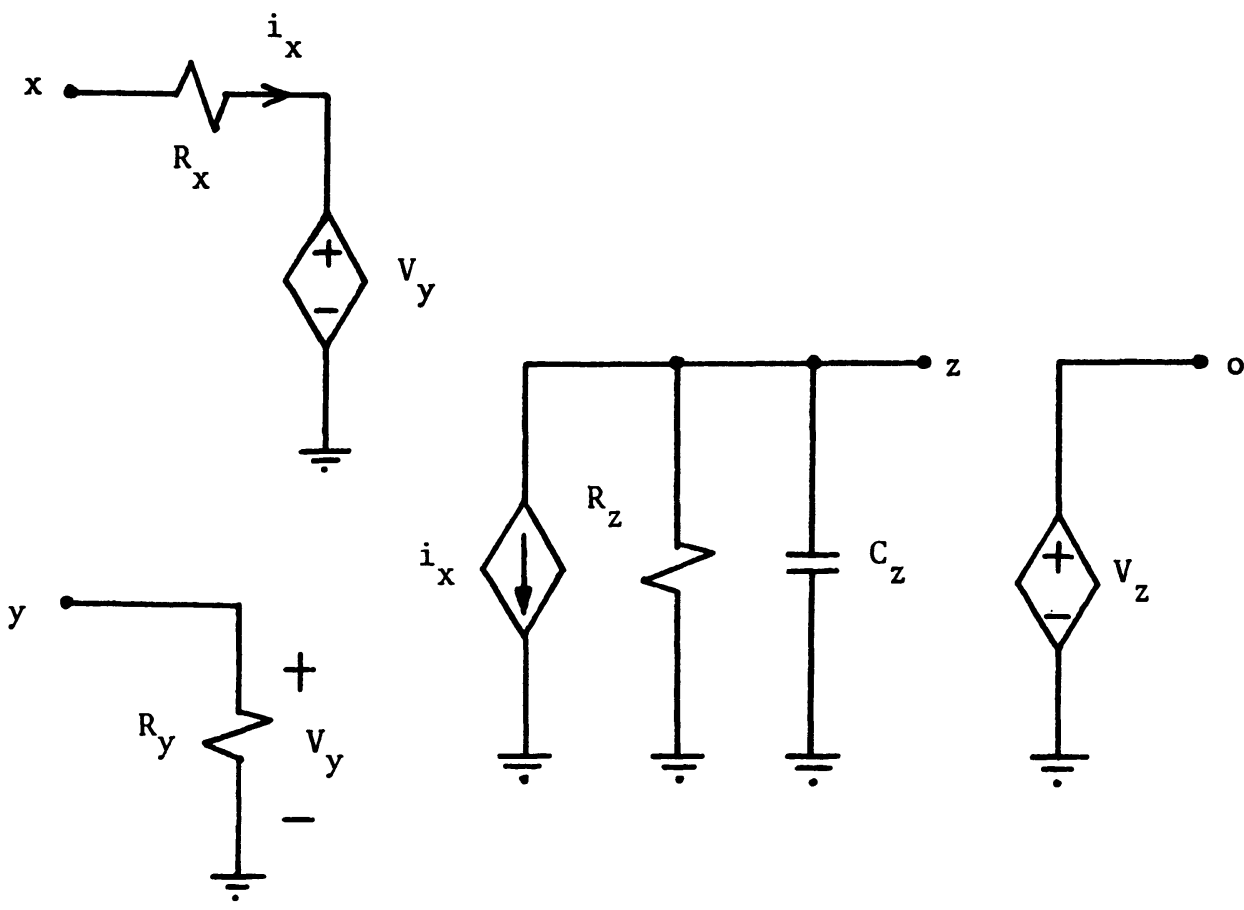

FIGURE 2 Modelling Parasitics of CFOA. 
From (7) and (8), one can see that while the parasitic resistance $R_{x}$ will slightly affect the frequency of oscillation, it has almost no effect on the condition of oscillation.

\section{$\omega_{0}$ SENSITIVITIES}

The various sensitivity figures are calculated using the sensitivity definition

$S_{y}^{\omega_{0}}=\frac{\mathrm{y}}{\omega_{0}} \frac{\mathrm{d} \omega_{0}}{\mathrm{dy}}$

Using (9), the $\omega_{0}$ passive and active sensitivities for the two circuits were calculated and are given by

$S_{G_{1}}^{\omega_{0}}=S_{\mathbf{G}_{2}}^{\omega_{o}}=-S_{C_{1}}^{\omega_{o}}=-S_{C_{2}}^{\omega_{o}}=\frac{1}{2}$

and

$S_{\alpha}^{\omega_{0}}=S_{\beta}^{\omega_{0}}=S_{\gamma}^{\omega_{0}}=0$

From (11), one can see that the frequency of oscillation of the proposed oscillator circuit is insensitive to the current and voltage tracking errors of the CFOA.

\section{EXPERIMENTAL RESULTS}

The proposed sinusoidal oscillator circuit was experimentally tested using the AD844 CFOA. Fig. 3 shows the results obtained with $C_{1}=C_{2}=100 p F, R_{1}=196 \Omega$.

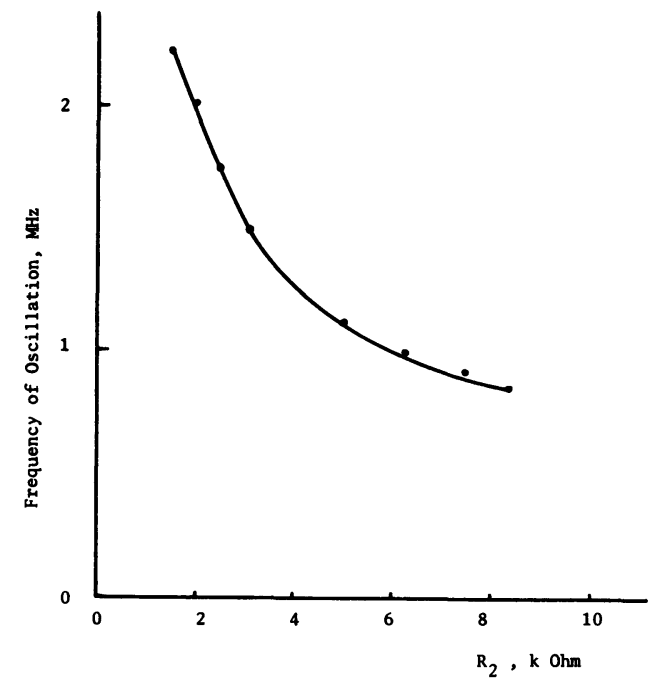

FIGURE 3 Measured Frequency of Oscillation with $R_{1}=196 \Omega, C_{1}=C_{2}=100 \mathrm{PF}$ 


\section{CONCLUSION}

A new single-frequency oscillator circuit using an ideal CFOA has been presented. The main features of the proposed circuit are:

1. Use of the minimum number of active and passive elements.

2. Low passive sensitivity characteristics.

3. Insensitive to CFOA parasitics as well as current- and voltage-tracking errors.

4. Uses two grounded capacitors and two resistors, one of them grounded. Thus, integration is feasible.

5. Low output impedance outlet. This is an advantage over high output impedance outlets of similar circuits using second-generation current-conveyors (CCII) [6].

\section{REFERENCES}

1. Celma, S., Martinez, P.A., and Carlosena, A., Current feedback amplifiers based sinusoidal oscillators, IEEE Transactions Circuits and Systems-I: Fundamental Theories and Applications, Vol. 41, 1994, pp. 906-908

2. Celma, S., Carlosena, A. and Martinez, P.A., Current feedback amplifiers based sinusoidal oscillators, International Symposium on Circuits and Systems, Vol.5, 1994, pp. 101-104

3. Liu, S.-I., Shih, C.-S. and Wu, D.-S., Sinusoidal oscillators with single element control using a current-feedback amplifier, International Journal of Electronics, Vol. 77, 1994, pp. 1007-1013

4. Abuelma'atti, M.T. and Al-Shahrani, S.M., A novel low-component-count single-elementcontrolled sinusoidal oscillator using the CFOA pole, International Journal of Electronics, Vol. 80, 1996, pp. 747-752

5. Svoboda, J.A., Comparison of RC op.-amp. and RC current conveyor filters, International Journal of Electronics, Vol. 76, 1994, pp. 615-626

6. Abuelma'atti, M.T. and Humood, N.A., Two new minimum-component Wien-bridge oscillators using current-conveyors, International Journal of Electronics, Vol. 63, 1987, pp. 669-672 

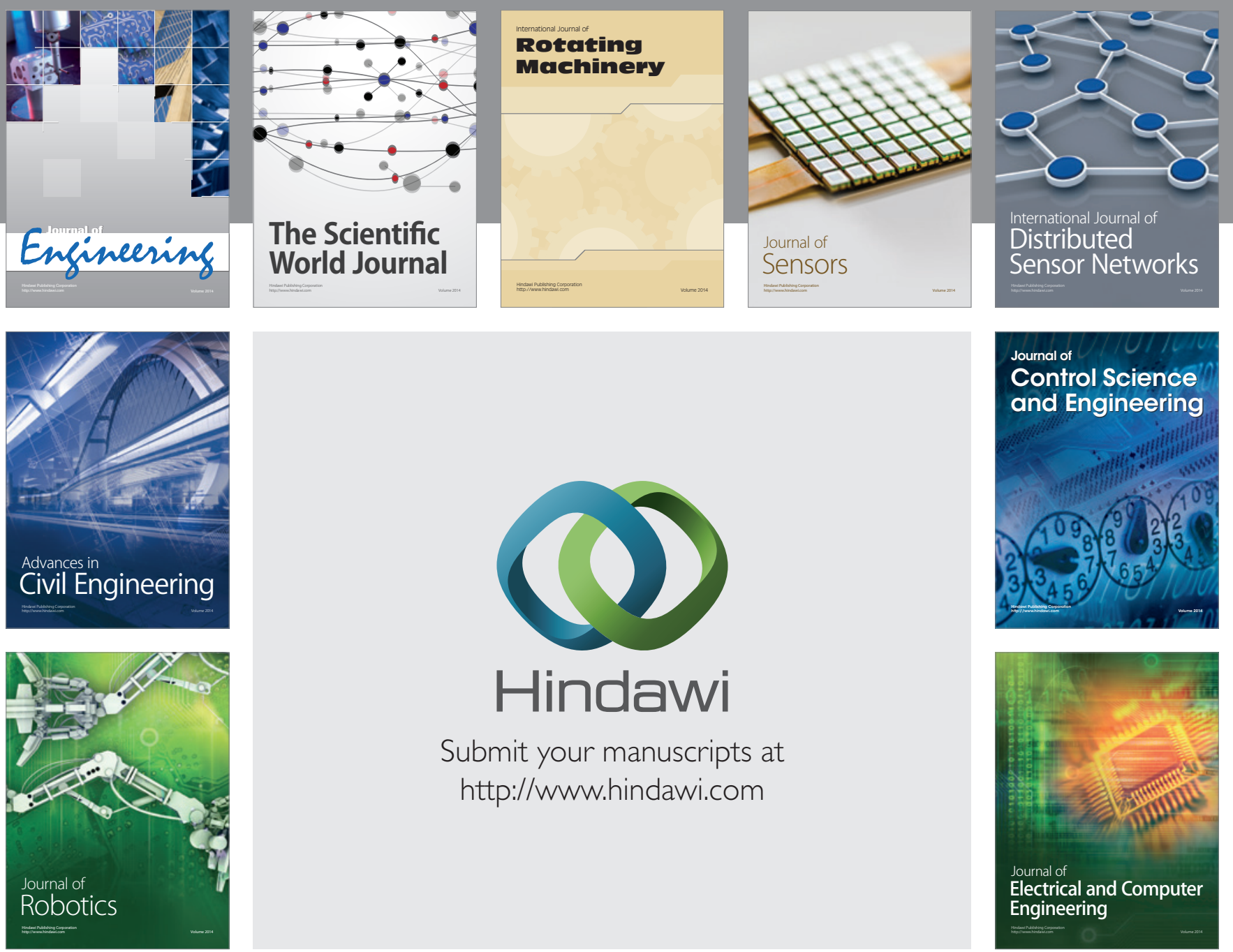

Submit your manuscripts at

http://www.hindawi.com
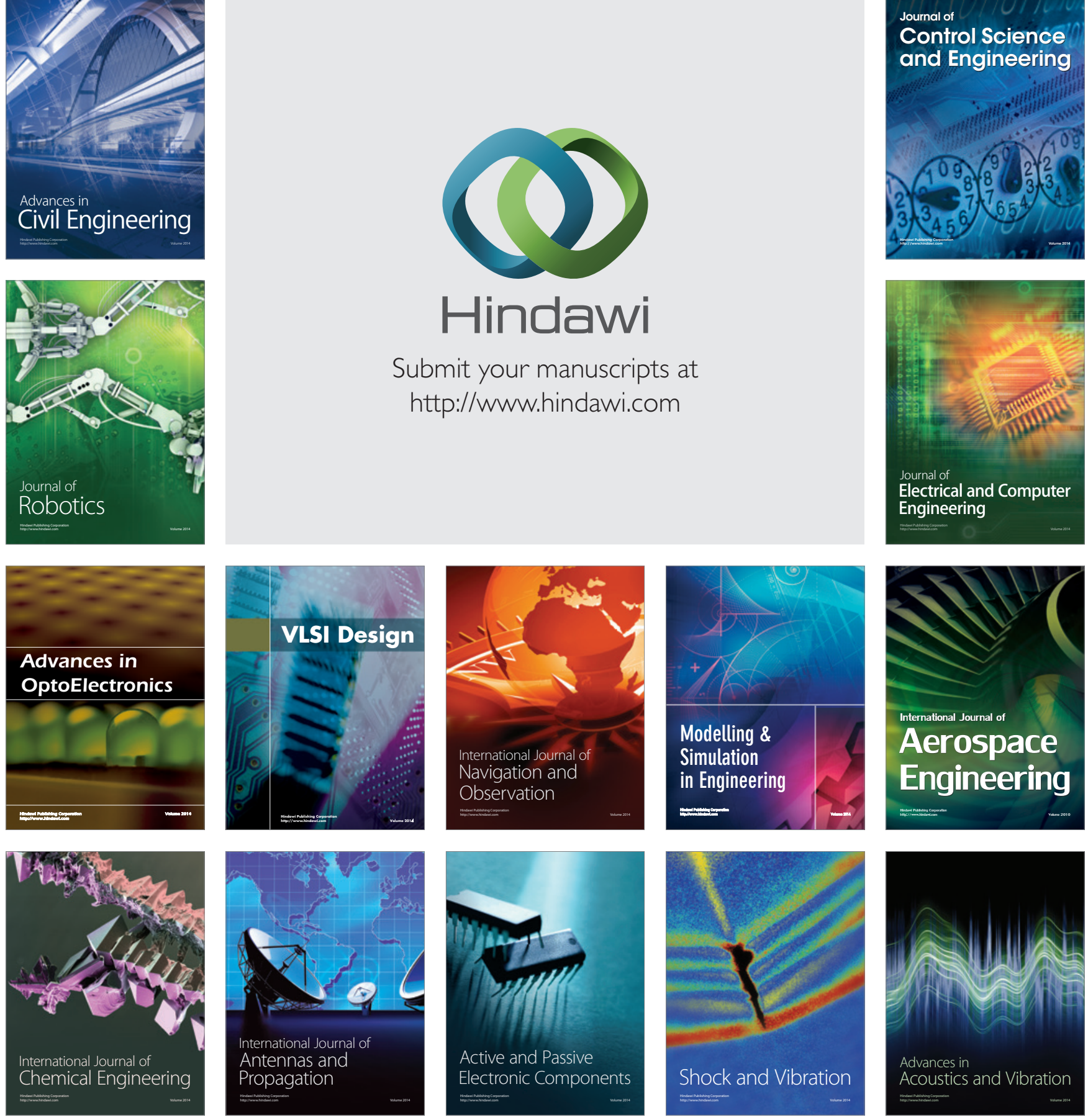